\title{
Traumatization and Trauma Cases: Childhood Adversity and Deafness
}

\author{
Trevor Archer $^{1 *}$ and Madeleine ET Zöller ${ }^{1,2}$
}

${ }^{1}$ Department of Psychology, University of Gothenburg, Sweden

${ }^{2}$ Affective Division, Psychiatric Unit for Deaf and Hard-Of-Hearing, Sahlgrenska University Hospital, Sweden

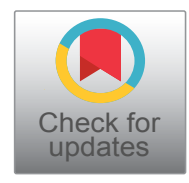

*Corresponding author: Trevor Archer, Department of Psychology, University of Gothenburg, Box 500, SE-45030 Gothenburg, Sweden, E-mail: trevor.archer@psy.gu.se

The association between adverse childhood experience and later adult psychological health has been well-documented. Thus, the presence of adult, parental, low income, social support and adult adversity are the avenues through which adverse childhood presents its influence upon psychological and somatic health deficits during adulthood [1]. The early childhood environment governs an early highly sensitive period for the development of regional brain circuitry for cognition and emotion, attention, self-control, well-being and stress-coping behaviors since the nurturing social experience during this time promotes the acquisition of social and cognitive skills and emotional competencies [2]. The huge bulk of longitudinal studies that are available show immeasurable evidence that children who, early in life, contend with chronic adversities, such as familial poverty, inappropriate care-giving, communicative neglect and childhood maltreatment are more likely to experience a broad range of impairments later on during their lives [3]. Familial, environmental and socioeconomic adversity form the background for childhood critical risk factors that include family strain and dysfunction, offspring insecurity, stress, emotional turmoil, low self-esteem, and poor mental health; stress and emotional turmoil, especially shape the propensities for 'bad-food' diets, self-medication and subtle addiction, and maladaptive behaviors applied to alleviate distressing psychological and emotional states [4]. Among South African university students a marked relationship has been shown between early childhood adversity, the presence of recent stressors, and depressive symptoms [5]. With regard to the relationship between childhood adversity and 'deaf-and-hard of hearing', it has been observed that amount of family time and routines, social support networks, communication affirmation, family hardiness, problem-solving skills, religion, the search for meaning, and acceptance of the child's hearing status were all associated with the development of family resilience [6]. Finally, it has been found that in otherwise healthy adults early childhood adversity, at low-to-moderate levels, was associated with altered basal hypothalamus-pituitary-adrenal axis activity during adulthood [7]. The present account examines the influences of childhood adversity upon later psychological and somatic health and functioning at adulthood with particular reference to adversity/abuse during childhood experienced by the deaf-and-hard of hearing community.

\section{Childhood Trauma}

Cases of childhood abuse, which are acts of commission, encompassing (i) Neglect of the child, which are acts of omission related to child care thereby causing potential or factual harm to the infant-child-adolescent, such as cases of inadequate health care, education, supervision, protection from hazards in the environment, and neglected basic needs, such as clothing and food, (ii) Physical abuse, such as beating, shaking, burning, and biting with the threshold for defining corporal punishment as abuse being unclear, (iii) Psychological abuse such as verbal abuse, humiliation, and acts that scare or terrorize a child, which may result in future psychological illness of the child, and (iv) Sexual abuse such as involvement of dependent, developmentally immature children (even infants) and adolescents in sexual activities which they do not fully comprehend, to which they are unable to give consent, or that violate both the social taboos and legislation regarding inviolability of fam-

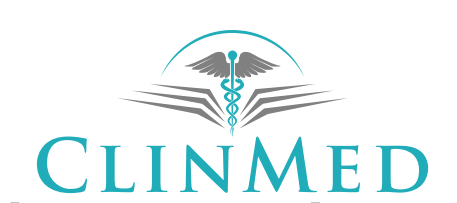

INTERNATIONAL LIBRARY

Citation: Archer T, Zöller MET (2018) Traumatization and Trauma Cases: Childhood Adversity and Deafness. Trauma Cases Rev 4:060. doi.org/10.23937/2469-5777/1510060

Accepted: June 12, 2018: Published: June 14, 2018

Copyright: (C) 2018 Archer T, et al. This is an open-access article distributed under the terms of the Creative Commons Attribution License, which permits unrestricted use, distribution, and reproduction in any medium, provided the original author and source are credited. 
ily roles. Surprisingly, most individuals interviewed the mental health services appear rarely, or never, posed questions pertaining child abuse or neglect, with male staff members asking less often than female staff members. Nevertheless, the history of any type of childhood abuse, more so than adversity, is related markedly with any type of medical disorder, and an elevated frequency of medical disorders among adult patients presenting a diagnosis of bipolar disorder [8]. Remarkably, the incidence of only $28 \%$ of abuse or neglect cases was identified and discovered in the clients' files from twenty-one relevant studies concerning this situation: Of those was listed the incidence of (a) Emotional abuse, 44\%; (b) Physical abuse, 33\%; (c) Sexual abuse, 30\%; (d) Emotional neglect, 17\%; (e) and Physical neglect, 10\% [9]. To be sure of correctly and accurately diagnosing incidences of child abuse or neglect, presiding physicians are required to be cognizant with disorders and medical conditions that may simulate maltreatment. In this context, the case of a two-year-old boy, hospitalized on two occasions due to suspicious injuries and wounds combined with psychosocial perspicuous indications, from a family situation recognised for its repeated proclivities for endangering of the child's well-being has been described [10]. Following the child's first hospitalization with wounds indicative of child abuse predilections, but lacking paraclinical abnormalities, medical inspections were arranged periodically such the child was hospitalized when signs of repeated child abuse were observed again five months later. During the course of the second admission, an acute case of lymphoblastic leukemia was revealed by intermittent laboratory examination, which were ordered from the presence of new bruises with changes in morphology, identifiable as petechial hemorrhages. The case of this two-year-old child illuminates the prevailing issues surrounding known cases of leukemia in childhood related to suspected child abuse thereby providing an illustration of probable illnesses that mimic instances of maltreatment.

Cases of economically-disadvantaged and ethnic-social minority children presenting injuries that are related to child abuse incidents are evaluated and diagnosed for abuse differentially. Social-ethnic intuition and informational background provide strategies for deriving differential diagnosis in the physical child abuse decision-making processes [11]. Child abuse or non-accidental trauma amongst children persists as a US-national disgrace and disease-epidemic endowing permanent health hazards effects when left untreated an undiscovered in the clinical setting; to this purpose the higher levels of prevalence of non-accidental child trauma at American College of Surgeons' verified Pediatric Trauma Centers offer evidence of increasingly greater measures of trauma among pediatric trauma patients as the result of more comprehensive experience and training of clinicians [12]. It must be considered that children with abuse who are admitted to the intensive care units may present high mortality and morbidity with commonly required immediate critical care; among neglected and abused children mortality rates reached $9.86 \%$, a frightening statistic [13]. Childhood trauma has been found to provide the origin for multiple expressions of psychopathology [14-16]. It has been registered that amongst an assembly of Palestinian children, it was observed that a large proportion, $43 \%$ of those participating, reported playing or visiting a nice place as earliest memories, and about one third $(30 \%)$ of the traumatic events or accidents $(30 \%)$ or miscellaneous events $(27 \%)$ linked to the memories [17]. The individual and social orientations of these children were almost equally common, the emotional tone mainly neutral (45.5\%), with $60 \%$ remembering a specific event/episode. Furthermore, the boys remembered a greater number of earliest memories involving traumatic events or accidents, whereas girls remembered more social events. As a related issue, the trauma of war was linked to decreased positive affective status and with a heightened specificity for these memories. Marked extents and accumulations of child abuse cases involving sexual abuse are missed frequently by healthcare providers and administrators leading to an increased risk of ongoing abuse. Increasing amount of studies are focusing on sentinel events, minor inflicted injuries noticed by a physician and/or parent(s) that initially are not considered a form of child maltreatment, but eventually, with continued abuse, are diagnosed as child abuse [18].

Childhood adversity, as observed through cases of abuse and neglect, exerts a powerful influence the intactness of neuropsychiatric health and well-being. For example, childhood physical abuse, and through concurrence accompanying trauma, depressive symptoms and sleep quality were associated markedly with the positive and negative symptoms of schizophrenia and general psychopathology [15]. Trauma/neglect during the infancy-child years, and in particular sexual abuse, has been found to be associated with sexual risk behaviors during later adolescent-adult life with connections to between sexual abuse and sex trade in the young adulthood period [19]. Childhood maltreatment, whether abuse, neglect or both, is linked strongly to the eventual development of substance abuse disorders with cognitive impairments mediating the relationship between childhood trauma and the expressions of substance abuse disorders [20]. Among 191 in-patients presenting alcohol use disorder childhood physical abuse mediated the relationship between ADHD and the severity of dissociative experiences [21]. In addition to the risk for later psychiatric and somatic pathology, recipients of childhood adversity present markedly smaller regional volumes of the dorsal anterior cingulate cortex in comparison with healthy control participants, a consistent finding in traumatized youths and adults [22]. Alarmingly, the presence of emotional or sexual abuse-trauma was associated with borderline personality disorder 
or ADHD or borderline disorder-ADHD co-morbidity in adulthood, as well as more general psychopathology [23].

\section{Deafness Trauma among Psychiatric Patients}

The definition of trauma in Deaf and Hard-of-Hearing persons $(\mathrm{DHH})$ is sometimes described as depending on the person's subjective experience of whether an event is traumatic or not. Among the factors proposed to influence reactions to trauma are biological vulnerability, which according to WHO [24] may include disabling hearing loss defined as a hearing loss greater than $40 \mathrm{~dB}$ in the better hearing ear. Factors that may complicate the problem of hearing loss are age at traumatic events, social context, life events and the severity of the stressor. Childhood adversity among the deaf may arise for several reasons, including increased risk for maltreatment, lack of recognition of this type of maltreatment, failure to provide a sign language early in the child's development, social and emotional isolation, lack of cognitive stimulation, and critically emotional and cognitive neglect that constitute a major stressor for the developing individual [25] and communication issues and food insecurity $[26,27]$. The identification as Deaf belonging to the Deaf community or hard-of-hearing belonging either to the Deaf culture or the hearing community or both may be a traumatic experience or on the other hand it may be a sheltering factor giving security. Currently, the recent developments in new instruments record observations on communication and social behaviors/events that serve as indicator items for children and adolescents hat have been deprived of family conversations and spent time on their own [28].

\section{Language Deprivation and Emotional Distur- bances}

Many deaf individuals comprise a unique linguistic minority group where they identify themselves with the Deaf culture [29]. Some experiences overlap with trauma in the general population, but many are unique to Deaf people as lack of communication good enough for them to be at ease with the hearing community. Language deprivation is a large problem. Zöller \& Archer [30] found that the communication between family members was hampered by a high rate of non-fluent communication in Swedish Sign Language within the families of the patients (86\%). Most of the deaf patients rely on parents that are hearing (94\%). Some of the patients have deaf siblings (15\%), and few of the deaf patients used some sign language with their family $(12 \%)$. Only ten percent of the patients were found to have fluent Swedish language skills. The results are in line with Black \& Glickman [31] who found that $75 \%$ of deaf individuals fell into the non-fluent range of communication in American Sign Language. Less than $8 \%$ of deaf children have been reported to receive regular access to sign language in their homes (Institute GR) [32] and in the study by $\varnothing$ hre, et al. [33] $15 \%$ of the patients using Norwegian Sign Language had signing parents. The data thus points clearly to the risk of language deprivation and is in the same level as was reported by Mitchell \& Karchmer [34] who report that more than $90 \%$ of deaf children are born to hearing parents.

Emotional disturbances are connected to language deprivation [35] investigated associations between positive mood and impulsiveness in DHH patients with psychiatric diagnoses compared to a healthy hearing control group. Significantly less optimism and positive was found in the DHH group. The DHH group had also significantly higher extern locus of control, identified regulation, external regulation, amotivation, distractiveness, and motor impulsiveness. However, no significant difference was found in internal locus of control and non-planning impulsiveness. Further results showed that positive mood was predicted by optimism and motor impulsiveness and was counter predicted by amotivation and distractiveness. Brown and Cornes [36] studied self-reported mental health in DHH teenagers. The conclusion was that the "language used at home" was the only significant predictor of mental health problems. There is an agreement among researchers that it is a risk for non-optimal development both if the signing children communicate with non-signing parents and if the children with partial hearing communicate with the same spoken language as the parents.

There is also a wider problem than language deprivation and emotional disturbances for this group of $\mathrm{DHH}$ psychiatric patients. A possible neurodevelopmental disorder with sociocultural origins has been held to be due to language deprivation [37]. Though there are very limited empirical data, there seems to be a mental health syndrome observed by clinicians working with deaf patients. In this syndrome Hall, et al. include language dysfluency, knowledge deficits, and disruptions in thinking, mood and/ or behavior. The complex interaction between self-rated affective mood as well as the combined double burden of affective psychiatric disorders and DHH was examined by Zöller \& Archer [30] who termed this specific syndrome the Affective Deaf Syndrome (ADS). DHH psychiatric patients were compared with healthy individuals. Significantly less positive affect, energy, self-esteem, affective mood, and watching television were found in the $\mathrm{DHH}$ group and significantly more negative affect, pain, non-prescribed analgesics and stress in the same group. Zöller \& Archer clarified some characteristics of ADS among the patient group. Analgesics were found to be counter-predictive for positive Affective Mood and identified as a risk-factor, however self-esteem was predicted for positive Affective Mood and considered a protecting factor. All these reactions may lead to a more isolated and restricted life. Immaturity, impulsiveness, explosiveness, and general lack of skills have been described as characterizing behaviors of deaf persons $[38,39]$. It has been argued that these behaviors are due to language deprivation [40]. 


\section{Traumatization in Deaf and Hard of Hearing Individuals}

Deafness and hard-of-hearing may lead to a heightened degree of stress, vulnerability and tiredness. According to this information research has shown that the mental and physical ill-being is higher within this group than in the general population. Often the ability to reach health-care is restricted due to the difficulty of communication, which sometimes increases the risk of these persons to get the wrong diagnosis or being maltreated. In one of the first large-scale trauma studies with the Deaf community, the California Deaf Trauma Study [41-43] discuss the result of hearing loss as having psychosocial consequences and suggest that the term information deprivation trauma (IDT) to describe this. IDT is a concept that requires a negative emotional response that is characterized by "(a) A lack of understanding of the extent, magnitude, consequences, and probability of a current or impending meaningful event; and (b) An inability to access information about this event that would reasonably allow a person to prepare, appropriately respond, or self-protect" [43]. They argue that IDT is a context variable and a meaningful subtype of trauma experience. The authors believe that information deprivation constitutes a potentially traumatic experience. Carlson \& Dalenberg [44] holds that it is possible that IDT may increase vulnerability to traumatization from the event itself by negatively affecting controllability, predictability and negativity and thereby changing the nature of the following symptoms. Schild \& Dalenberg [45] report that Deaf adults were significantly higher in psychoform dissociation than the norm samples of hearing adults. It was also confirmed that in hearing samples "those dissociative PTSD displayed significantly more symptoms of depression, anger, impaired self-reference, tension reduction behavior, and somatoform dissociation than did the nondissociative PTSD group". Nijenhuis [46] has given ten reasons for classifying PTSD as a dissociative disorder. Schild and Dalenberg [45] report that the posttraumatic stress disorder (PTSD) is underdiagnosed in the deaf population. The problem is that only about $20 \%$ of the patient group meets the criteria for PTSD because e.g. they don't clearly report the startle response and detachment from others. However, the result is often that the deaf and hard-of-hearing persons withdraw from society and from working life due to this and other difficulties. Isolation may occur and disempowerment.

There seems to be an agreement that the group of $\mathrm{DHH}$ individuals are more at risk of trauma and traumatic reactions than the general population $[29,47$ 49]. Landsberger highlights the fact that children with disabilities are 3.4 times more likely to be abused than children without these difficulties and that the $\mathrm{DHH}$ children and adolescents may be twice as likely to experience different kinds of abuse and neglect. $\varnothing$ hre, et al.
[50] found in a clinical study on adult psychiatric outpatients that all patients reported traumatic events with a mean of 6.2 different types. Eighty-five percent of patients reported subsequent traumatization with clearly negative impacts, however these were not significantly associated with residential school or the communicative competence of the childhood caregivers. The most common type of traumatic events was of a relational character: Emotional neglect and abuse by close family members and family problems in childhood. Interpersonal traumatic experiences and neglect impact individuals' development and growth. Johnston-McCabe, et al. [51] found that $71 \%$ of DHH outpatients that they had been exposed to emotional and psychological abusive behavior in adult life. This is also the clinical experience from the work among our DHH psychiatric patients at the psychiatric clinic in Göteborg, Sweden.

\section{Conclusions}

Childhood adversity, consisting of physical and sexual abuse and neglect, implies a high degree of suffering and psychopathology that, most disconcertingly and alarmingly, persists throughout the lifespan. Furthermore, the extent of trauma remains an open issue since an unknown and uncounted number of causes are missed frequently by healthcare providers and administrators leading to an increased risk of ongoing abuse. The role of empowerment, self-advocacy, and social relations over life span are important aspects to consider for a healthy life. There are some indications that self-esteem may predict positive affect for this patient group, i.e. deaf and hard-of-hearing, and may be identified as a protective factor [30].

\section{References}

1. Jones TM, Nurius $P$, Song C, Fleming CM (2018) Modeling life course pathways from adverse childhood experiences to adult mental health. Child Abuse Negl 80: 32-40.

2. Lomanowska AM, Boivin M, Hertzman C, Fleming AS (2017) Parenting begets parenting: A neurobiological perspective on early adversity and the transmission of parenting styles across generations. Neuroscience 342: 120-139.

3. Hertzman C (2013) The significance of early childhood adversity. Paediatr Child Health 18: 127-128.

4. Hemmingsson E (2018) Early childhood obesity risk factors: Socioeconomic adversity, family dysfunction, offspring distress, and junk food self-medication. Curr Obes Rep 7: 204-209.

5. Mall S, Mortier P, Taljaard L, Roos J, Stein DJ, et al. (2018) The relationship between childhood adversity, recent stressors, and depression in college students attending a South African university. BMC Psychiatry 18: 63.

6. Ahlert IA, Greeff AP (2012) Resilience factors associated with adaptation in families with deaf and hard of hearing children. Am Ann Deaf 157: 391-404.

7. Kuras YI, Assaf N, Thoma MV, Gianferante D, Hanlin L, et al. (2017) Blunted diurnal cortisol activity in healthy adults with childhood adversity. Front Hum Neurosci 11: 574.

8. Hosang GM, Fisher HL, Uher R, Cohen-Woods S, Maughan 
B, et al. (2017) Childhood maltreatment and the medical morbidity in bipolar disorder: A case-control study. Int J Bipolar Disord 5: 30.

9. Read J, Harper D, Tucker I, Kennedy A (2017) Do adult mental health services identify child abuse and neglect? A systematic review. Int J Ment Health Nurs 27: 7-19.

10. Woydt L, König C, Bernhard MK, Nickel P, Dreßler J, et al. (2017) The importance of laboratory re-evaluation in cases of suspected child abuse - A case report. Leg Med (Tokyo) 28: $27-30$.

11. Keenan HT, Cook LJ, Olson LM, Bardsley T, Campbell KA (2017) Social intuition and social information in physical child abuse evaluation and diagnosis. Pediatrics 140.

12. Bogumil DDA, Demeter NE, Imagawa K, Upperman JS, Burke RV (2017) Prevalence of non-accidental trauma among children at ACS verified pediatric trauma centers. J Trauma Acute Care Surg 83: 862-866.

13. Lee EP, Hsia SH, Huang JL, Lin JJ, Chan OW, et al. (2017) Epidemiology and clinical analysis of critical patients with child maltreatment admitted to the intensive care units. Medicine (Baltimore) 96: e7107.

14. Asselmann E, Stender J, Grabe HJ, König J, Schmidt CO, et al. (2018) Assessing the interplay of childhood adversities with more recent stressful life events and conditions in predicting panic pathology among adults from the general population. J Affect Disord 225: 715-722.

15. Kilicaslan EE, Esen AT, Kasal MI, Ozelci E, Boysan M, et al. (2017) Childhood trauma, depression, and sleep quality and their association with psychotic symptoms and suicidality in schizophrenia. Psychiatry Res 258: 557-564.

16. Newbury JB, Arseneault L, Moffitt TE, Caspi A, Danese A, et al. (2018) Measuring childhood maltreatment to predict early-adult psychopathology: Comparison of prospective informant-reports and retrospective self-reports. J Psychiatr Res 96: 57-64.

17. Peltonen K, Kangaslampi S, Saranpää J, Qouta S, Punamäki RL (2017) Peritraumatic dissociation predicts posttraumatic stress disorder symptoms via dysfunctional trauma-related memory among war-affected children. Eur J Psychotraumatol 8: 1375828.

18. Gonzalez D, McCall JD (2017) Child Abuse and Neglect.

19. London S, Quinn K, Scheidell JD, Frueh BC, Khan MR (2017) Adverse experiences in childhood and sexually transmitted infection risk from adolescence into adulthood. Sex Transm Dis 44: 524-532.

20. Edalati H, Krank MD (2016) Childhood maltreatment and development of substance use disorders: A review and a model of cognitive pathways. Trauma Violence Abuse 17: 454-467.

21. Evren C, Umut G, Bozkurt M, Can Y, Evren B, et al. (2017) Partial mediator role of physical abuse on the relationship between attention-deficit/hyperactivity disorder symptoms and severity of dissociative experiences in a sample of inpatients with alcohol use disorder. Indian J Psychiatry 59: 306-312.

22. Rinne-Albers MA, Pannekoek JN, van Hoof MJ, van Lang ND, Lamers-Winkelman F, et al. (2017) Anterior cingulate cortex grey matter volume abnormalities in adolescents with PTSD after childhood sexual abuse. Eur Neuropsychopharmacol 27: 1163-1171.

23. Ferrer M, Andión Ó, Calvo N, Ramos-Quiroga JA, Prat M, et al. (2016) Differences in the association between child- hood trauma history and borderline personality disorder or attention deficit/hyperactivity disorder diagnoses in adulthood. Eur Arch Psychiatry Clin Neurosci 267: 541-549.

24. World Health Organization (2014) Prevention of blindness and deafness: Grades of hearing impairment.

25. Humphries T, Kushalnagar P, Mathur G, Napoli DJ, Padden C, et al. (2016) Language choices for deaf infants: Advice for parents regarding sign languages. Clin Pediatr (Phila) 55: 513-517.

26. Kushalnagar P, Bruce S, Sutton T, Leigh IW (2017) Retrospective basic parent-child communication difficulties and risk of depression in deaf adults. J Dev Phys Disabil 29: 25-34.

27. Kushalnagar P, Moreland CJ, Simons A, Holcomb T (2018) Communication barrier in family linked to increased risks for food insecurity among deaf people who use American Sign Language. Public Health Nutr 21: 912-916.

28. Patrick DL, Edwards TC, Kushalnagar P, Topolski T, Schick $B$, et al. (2018) Caregiver-reported indicators of communication and social functioning for young children who are deaf or hard of hearing. J Deaf Stud Deaf Educ 23: 200208.

29. Landsberger SA, Sajid A, Schmelkin L, Diaz DR, Weiler C (2013) Assessment and treatment of deaf adults with psychiatric disorders: A review of the literature for practitioners. J Psychiatr Pract 19: 87-97.

30. Zöller MET, Archer T (2015) Emotional disturbances expressed by deaf patients: Affective deaf syndrome. Clin Exp Psychol 2: 109.

31. Black PA, Glickman NS (2006) Demographics, pychiatric diagnoses, and other characteristics of North American Deaf and hard-of hearing inpatients. J Deaf Stud Deaf Educ 11: 303-321.

32. Institute GR (2011) Regional and national summary report of data from the 2009-2010 annual survey of deaf and hard of hearing children and youth. 1-12.

33. Øhre B, Volden M, Falkum E, Tetzcher SV (2017) Mental disorders in deaf and hard of hearing adult outpatients: A comparison of linguistic subgroups. J Deaf Stud Deaf Educ 22: $105-117$.

34. Mitchell RE, Karchmer MA (2004) Chasing the mythical ten percent: Parental hearing status of deaf and hard of hearing students in the United States. Sign Language Studies 4: 138-168.

35. Zöller MET, Schütz E, Archer T (2016) Mood and impulsiveness in affective deaf syndrome. Journal of psychiatry and psychology research. Well-being, Empowerment and Affective Profiles 1.

36. Brown PM, Cornes A (2015) Mental health of deaf and hard-of-hearing adolescents: What the students say. Journal of Deaf Studies and Deaf Education 20: 75-81.

37. Hall CW, Levin LL, Andersson ML (2017) Language deprivation syndrome: A possible neurodevelopmental disorder with sociocultural origins. Soc Psychiatry Epidimiol 52: 761-776.

38. Denmark JG, Warren $F$ (1972) A psychiatric unit for the deaf. Br J Psychiatry 120: 423-428.

39. Altshuler KZ (1986) Perceptual handicap and mental illness, with special reference to early profound deafness. Am J Soc Psychiatry 6: 125-128.

40. Kitson N, Fry R (1990) Prelingual deafness and psychiatry. Br J Hosp Med 44: 353-356. 
41. Schild S, Dalenberg CJ (2012) Trauma exposure and traumatic symptoms in deaf adults. Psychological Trauma: Theory, Research, Practice, and Policy 4: 117-127.

42. Schild S, Dalenberg CJ (2015) Consequences of childhood and adult sexual and physical trauma among deaf adults. Journal of aggression, Maltreatment \& Trauma 24: 237256.

43. Schild S, Dalenberg CJ (2016) Information deprivation trauma: Definition, assessment, and interventions. Journal of Aggression, Maltreatment \& Trauma 25: 873-889.

44. Carlson EB, Dalenberg CJ (2000) A conceptual framework for the impact of traumatic experiences. Trauma, Violence \& Abuse 1: 4-28.

45. Schild S, Dalenberg CJ (2012) Psychoform and somatoform dissociation and PTSD in deaf adults. J Trauma Dissociation 13: 361-376.

46. Nijenhuis ERS (2017) Ten reasons for conceiving and clas- sifying posttraumatic stress disorder as a dissociative disorder. European Journal of Trauma \& Dissociation 1: 47-61.

47. Pereira PC, Fortes PA (2010) Communication and information barriers to health assistance for deaf patients. Am Ann Deaf 155: 31-37.

48. Fellinger J, Holzinger D, Pollard R (2012) Mentl health of deaf people. Lancet 379: 1037-1044.

49. Rönnberg J, Lunner T, Zekveld A, Sorqvuist $P$, Danielsson $T$, et al. (2013) The ease of language understanding (ELU) model: Theoretical, empirical, and clinical advances. Front Syst Neurosci 7: 31.

50. Øhre B, Uthus MP, von Tetzchner S, Falkum E (2015) Traumatization in deaf and hard-of-hearing adult psychiatric outpatients. J Deaf Stud Deaf Educ 20: 296-308.

51. Johnston MP, Levi MM, Van Hasselt VB, Vanderbeek A (2011) Domestic violence and social support in a clinical sample of deaf and hard of hearing women. Journal of Family Violence 26: 63-69. 